\title{
Risa y poesía. Cinco momentos centroamericanos ${ }^{1}$
}

\author{
(Laughter and Poetry: \\ Five Moments in Central America)
}

\section{Guillermo Molina Morales² \\ Instituto Caro y Cuervo, Colombia}

\begin{abstract}
ReSUMEN
Se desarrolla un análisis, desde lo temático, discursivo y cultural, de cinco momentos de la poesía centroamericana, como manifestaciones de sendos modos de representación de la risa, como opción estética. Se analiza el desarrollo desde la poesía decimonónica humorística, el modernismo y sus alternativas, la poesía sociopolítica, la visión metafísica con su contraparte irónica y la novelización de la poesía. El entorno conceptual que fundamenta el estudio es la tesis de que con la Modernidad se rompen vinculaciones de la poesía con nociones como la belleza o el bien, a favor de un internamiento en aspectos esenciales del discurso como tal y su significado en el entorno histórico, como proceso creativo y como ejercicio de lectura.
\end{abstract}

1 Recibido: 12 de setiembre de 2019; aceptado: 31 de enero de 2020. Esta es la versión ampliada de la conferencia dictada por su autor en el coloquio Literatura, humor y risa, celebrado en la Facultad de Filosofía y Letras, de la Universidad Nacional (Costa Rica), entre el 3 y el 6 de setiembre de 2018.

2 Correo electrónico: Guillermo.Molina@caroycuervo.gov.co

Letras 68 (2020), ISSN 1409-424X; eISSN 2215-4094 


\begin{abstract}
Five moments of Central American poetry are analyzed thematically, discursively and culturally, as manifestations of the respective ways of representing laughter, as an esthetic option. Its development is analyzed beginning with $19^{\text {th }}$-century humorous poetry, modernism and its alternatives, sociopolitical poetry, the metaphysical vision with its ironic counterpart, and the novelization of poetry. The conceptual setting underlying the study is the thesis that with Modernity, links between poetry and notions such as beauty or good are broken in favor of an internment in essential aspects of discourse as such and its meaning in the historical setting, as a creative process and as an exercise in reading.
\end{abstract}

Palabras clave: literatura centroamericana, la risa en la poesía, poesía centroamericana y modernidad, poesía costarricense contemporánea

Keywords: Central American literature, laughter in poetry, Central American poetry and modernity, contemporary Costa Rican poetry

Las relaciones entre risa y poesía siempre han sido problemáticas. El origen del desencuentro es la concepción de la poesía como lenguaje elevado y autosuficiente, asociado a la belleza. La belleza es, por definición, perfecta e inmutable y no admite las rupturas de la risa. Sobre todo, porque la risa es igualitaria y, en cambio, la búsqueda de la belleza impone unas jerarquías basadas en un pensamiento dogmático. Esta concepción exclusivamente seria fue predominante durante una etapa histórica que podemos denominar «primera modernidad» (entre los siglos XVI y XVIII). El contrapunto humorístico se refugió en las formas populares, presentes tanto en la poesía oral como en la culta (piénsese en la vertiente popular de autores como Góngora, Quevedo o Sor Juana).

La poesía en la Modernidad tiene un carácter distinto. Su misión es la exploración en la condición humana. Tal carácter 
reflexivo estaba ausente en la poesía clásica, precisamente por su rigidez dogmática. En este sentido, la poesía se acerca a otros géneros literarios, al incorporar la duda dinámica y abrirse a diferentes perspectivas y discursos. De aquí proviene el concepto de «novelización» de la poesía, que explicaremos más adelante. La poesía deja de considerarse un discurso autosuficiente, por lo que su diferencia debe ubicarse en el ámbito de lo cuantitativo (intensidad).

Debido a esa apertura, y a la tendencia a fusionar diversas líneas estéticas, la Modernidad propicia el retorno a la risa como característica radical del discurso poético. Así, la «tradición de la ruptura» que caracteriza los últimos dos siglos se ha alimentado de sucesivas recuperaciones de aspectos excluidos en la seriedad clásica. Entre otros rasgos, podemos citar los referentes cotidianos, el lenguaje coloquial, la inclusión de otros lenguajes (desde el científico hasta el publicitario), e incluso la utilización de un simbolismo tradicional.

En Latinoamérica, la concepción de la poesía presenta una evolución análoga, aunque debamos alargar el periodo de pervivencia del clasicismo. Durante casi todo el siglo XIX, se mantuvo el dominio de la concepción seria de la poesía, lo que se explica por la necesidad que tenían las élites de las nuevas repúblicas de forjarse un discurso elevado que unificara y guiara el imaginario de la nación. La independencia política de los países hispanoamericanos no supuso su independencia estética; por el más bien al contrario. El punto de corte se situaría en el Modernismo, que, como sostienen cada cual por su lado, Gutiérrez Girardot y Octavio $\mathrm{Paz}^{3}$, no es principalmente una tendencia estilística, sino una cosmovisión que supone la entrada a la Modernidad en nuestro continente. Por esto mismo, la crítica actual tiende a relegar el estudio de la poesía decimonónica: solo a partir de Rubén Darío podemos percibir una sensibilidad que es ya nuestra.

3 Rafael Gutiérrez Girardot, Modernismo (Barcelona: Montesinos, 1983): Octavio Paz, Los hijos del limo (Barcelona: Seix Barral, 1987). 
En el caso de la crítica, la apertura a la comprensión de la risa ha sido posterior. Todavía hoy encontramos, en ocasiones, una interpretación literaria basada en la seriedad excluyente, lo que genera importantes distorsiones. Por ejemplo, en un tema tan sensible como las visiones sobre la Conquista. Así, Juan de Castellanos, autor del poema épico más extenso de la lengua española, siempre se ha visto como portador de una visión imperialista, que en el siglo XIX se alababa y en el Xxi se impugna. Los numerosos fragmentos donde prima la risa, se ignoran o se atribuyen a la impericia e incluso al carácter vicioso del escritor. Sin embargo, lo que estos pasajes demuestran es que el patetismo heroico convivía con una tendencia igualitaria enraizada en lo popular. Hasta tal punto es así, que encontramos coincidencias entre la visión de los indígenas sobre la Conquista, calificando al papa de borracho y al rey de loco (según relata Fernández de Enciso), y la visión de los copleros populares, según los reproduce el propio Castellanos (el caso de Juan Martín).

Otro ejemplo de distorsión, cambiando de lugar y de época, sucede en los estudios sobre la poesía de Guatemala en el siglo XIX. Poetas como José Batres Montúfar y Josefa García Granados se han valorado por su tono melancólico, que roza hasta lo cursi, mientras que se ha dejado de lado la alegría y la procacidad de poemas como el «Sermón para José María Castilla»: «todos quieren joder, hembras y machos / jóvenes, viejos, niños y muchachos», dice este canto a la carnalidad. Claro que este tipo de versos no se pueden enseñar en los colegios de la Patria, puesto que la homogeneidad del grupo requiere de ideales imaginariamente elevados.

Teniendo en cuenta estas premisas, el presente artículo explora cinco momentos de la poesía centroamericana como representativos de las distintas maneras en que la risa ha configurado la evolución estética. El recorrido será esquemático, pero trazará un panorama con diversos senderos que pueden recorrerse en futuras investigaciones. En conjunto, este escrito quiere aportar una mirada distinta para entender la poesía de Centroamérica, con énfasis en la costarricense. 
En concreto, a través de la estética histórica, con su mirada amplia basada en las grandes líneas de la imaginación literaria, se busca complementar los habituales enfoques basados en movimientos estilísticos (historia literaria tradicional) o en problemas ideológicos de corto alcance (poscolonialismo, estudios culturales, etc.).

\section{Seriedad y risa en los primeros poetas centroamericanos (siglo XIX)}

En la época colonial no hubo mucho desarrollo de la poesía culta en la región centroamericana, con la única excepción, no demasiado boyante, del territorio que hoy compone Guatemala, que albergaba el centro de poder regional (la Real Audiencia). La poesía popular era, sin duda, la más practicada en la época, incluso si nos limitamos a la minoría hispana. Poco hemos conservado de esta tradición oral, y suele deberse a la pluma de letrados que utilizaban formas populares: por ejemplo, el primer poema hispano conservado en territorio costarricense se debe al conquistador Domingo Jiménez (15351610 ?). Se trata de unas coplas que glosan una canción medieval, de tal forma que expresen una crítica contra el gobernador Anguciana.

Más interesante es el caso de José Trinidad Reyes (17971855), que hoy día se toma como prócer de Honduras, pero de cuya obra solo se han publicado y estudiado sus Pastoleras. Estas pequeñas piezas teatrales testimonian la supervivencia de una tradición popular en la que se insertan dramaturgos en verso como el «mexicano» González de Eslava (siglo XvI) y obras medievales como el Auto de los Reyes Magos. El resto de la obra poética de Reyes muestra la práctica de otros géneros populares, como el villancico o los curiosos «cuándos», que pueden relacionarse con los «cielitos» gauchescos de su contemporáneo Bartolomé Hidalgo. En cambio, se conservan algunos poemas patrióticos y amorosos en formas cultas y estilo neoclásico que no guardan relación con los anteriores, sino que señalan el creciente predominio de la ciudad letrada. 
Así pueden entenderse las primeras antologías de poesía local o regional, ya en la segunda mitad del siglo xIx. Su objetivo era crear el imaginario de una élite dominante a través de las estéticas de la seriedad, para lo cual se relegan la risa y lo popular. El proyecto se muestra en obras como la Lira costarricense $e^{4}$, que buscaba dar cuenta de la calidad de los ingenios criollos, pero cuyos poetas, como dijo Alberto Cañas, «no hay por dónde cogerlos». Afirman Monge y Baldotano que estamos ante una «una concepción del ejercicio literario asociada a la belleza del decir, a los temas universales (o eternos) y a un tratamiento elevado y sublime» ${ }^{5}$. En concreto, se configura un ideal patético (búsqueda de la belleza) o uno didáctico (búsqueda del bien) a través de temas como el amor o la patria. No hace falta buscar muy lejos los ejemplos. En el primer poema de Lira costarricense, el de José María Alfaro, encontramos «La virtud y la belleza / De la dulce madre mía $»^{6}$. En el segundo, del mismo autor, aparecen como modelos «Colón, Bolívar, Wáshington, los genios / que supieron hacer de nuestras almas / Conciencias vivas» ${ }^{7}$.

Es cierto que figuran piezas humorísticas en la antología, pero se trata de una risa burlesca, limitada al inocuo juego de palabras, que evita el componente crítico o popular. Son versos concebidos como juego social, sin intención artística. Ejemplo es el de Rafael Carranza, cuya «Letrilla» comienza: «Siguiendo el mismo consejo / Del chitón que es el mejor / No incurriré en el error / Y salvaré mi pellejo: / Esta es mi humilde opinión. / Chitón!»» ${ }^{8}$ Lo curioso es que en el epígrafe inicial se cita a Francisco de Quevedo, que no se caracterizaba precisamente por su boca cerrada. Este tipo de poemas era característico de las élites letradas, bajo el rótulo de «poesía

4 Máximo Fernández, ed., Lira costarricense: colección de composiciones y poetas de Costa Rica (San José: Tipografía Nacional, 1890-1891). Se cita por la edición facsimilar editada por la Editorial Universidad de Costa Rica, 1990.

5 Carlos Francisco Monge y Gabriel Baltodano Román, «Para una periodozación de la crítica literaria», Letras 60 (2016): 24.

6 Fernández, 5

7 Fernández, 12.

8 Fernandez, 155. 
festiva», un género muy popular en ciudades como Bogotá; poetas como Ricardo Carrasquilla o José Manuel Marroquín eran referentes expresos de los costarricenses.

Si ampliamos el espectro de la búsqueda a los periódicos, encontramos otro tipo de risa. Así, la antología de Batodano y Rojas muestra la importancia de la sátira política en el periodo comprendido entre 1860 y $1910^{9}$. Se trata de obras en verso cuya intención, de nuevo, no era artística, sino de combate directo contra el gobernante de turno. Aunque las formas utilizadas son casi siempre populares (claro predominio del verso octosílabo en estrofas como la décima, el romance o la letrilla), no encontramos aquí una conexión con el realismo grotesco tradicional. Se trata, más bien, de una risa parcial que solo muestra la cara crítica, pero no la renovadora, y que se limita a su contexto inmediato.

Siguiendo con la Costa Rica de finales del siglo XIX, es preciso detenernos en el autor más conocido: Aquileo Echeverría (18661909). Aunque en su tiempo fue considerado como poeta nacional, hoy prácticamente solo se lo conoce por dar nombre a los premios nacionales de cultura. Posiblemente, eso se debe a que su horizonte estético todavía no alcanza las coordenadas de la Modernidad (caracterizada, recordemos, por la fusión de seriedad y risa, de alta cultura y cultura popular). Es cierto que las Concherías tienen como objetivo recuperar el habla y la visión del mundo de las clases populares (de los «conchos»), pero este potencial no llega a permear la propuesta estética, sino que se relega al papel de curiosidad marginada. De esta manera, paradójicamente, se confirma la separación entre dos mundos y la superioridad de uno de ellos, el letrado.

Veamos como ejemplo lo que sucede en «La visita del compadre», que el sujeto poético y su esposa califican de «nuestro calvario». En español estándar, el sufrido protagonista introduce: «Todos ocupan la mesa; / yo les hago compañía / y guardo las apariencias, / y de lo que

9 Gabriel Baltodano y Lillyam Rojas, eds., Poesía de humor e ingenio. Costa Rica 1860-1910 (San José: Editorial de la Universidad Estatal a Distancia, 2013. 
hablo con ellos / va este botón como muestra $\rangle^{10}$. A continuación, en transcripción fonética dialectal, el campesino describe un matrimonio pantagruélico: «Duró la noche y el día, / los comimos la ternera / y'un chompipe y'un chanchillo, / y no sé cuántas cajuelas / de frijoles y de papas, / y de arroces y de alverjas. / Los bebimos un barril / de chinchiví con piñuela, / y entre cususa y rompope / como cuarenta limetas» ${ }^{11}$. Termina insinuando la ferocidad sexual de la novia en la noche de bodas. Encontramos aquí el grotesco festivo tradicional en todo su esplendor. Ahora bien, el paso de la oralidad a la escritura, y el marco propiciado por un narrador letrado que lo desprecia, sitúa la risa popular en un plano de inferioridad.

Echeverría (y, por lo tanto, sus seguidores) podrían haber encontrado nuevas soluciones ante el reto que suponía incluir el discurso popular en la poesía culta. El mayor ejemplo lo encontramos en la poesía gauchesca argentina. Pensemos en el Fausto de Estanislao del Campo. En esta obra, también se contraponen la cultura letrada (representación teatral del Fausto de Goethe) y la popular (interpretación del gaucho que la relata), pero se genera una dialéctica entre las dos culturas, capaz de señalar las falencias de las convenciones cultas. Por su parte, el Martín Fierro de José Hernández, en donde no se introduce expresamente el discurso letrado, explora las posibilidades «épicas» del lenguaje y universo gauchos, sin que exista un deseo de ridiculizarlos.

Sorprende que la crítica no haya encontrado grandes diferencias entre ambas recreaciones de lo popular. El propio Rubén Darío situaba en un mismo plano a Echeverría y a los poetas gauchescos. Los compatriotas del poeta, por su parte, tendían al elogio, lo que se explica al considerar que las Concherías ofrecen una estilización del «alma nacional» (idea, como se notará, de filiación romántica) $\mathrm{y}$, al mismo tiempo, la reafirmación de la superioridad letrada que

10 Fernández, 56.

11 Fernández, 57. 
debía guiar esa «alma» ${ }^{12}$. Es cierto que en algunos poemas parece existir cierta crítica a la élite, como en «La firmita», pero estamos de acuerdo con Quesada Soto quien afirma que «al no integrarlo coherentemente (...), ese elemento no se convierte en instrumento de denuncia o protesta explícita contra el sistema político del liberalismo patriarcal» ${ }^{13}$. Para hacerlo, Echeverría debería haber superado la división entre seriedad y risa.

\section{De princesas y bufones: Rubén Darío en la encrucijada de la Modernidad}

A diferencia de Echeverría, la Modernidad suscita una nueva fusión entre las distintas facetas de la imaginación literaria en un intento de aunar energías para la comprensión de un mundo complejo y heterogéneo. Este proceso comienza en Hispanoamérica a partir del Modernismo, con la correspondiente separación entre la figura del poeta y la del político, tan ampliamente imbricadas hasta entonces. La marginación del poeta le hace consciente de su fragilidad y le permite explorar nuevas opciones compositivas.

Estas importantes novedades comienzan con los poetas precursores del Modernismo, como el colombiano José Asunción Silva. Aunque todavía es recordado por sus sonoros poemas de amor y muerte, Silva muestra el desgarro de la Modernidad de forma más directa en un pequeño libro humorístico: Gotas $\operatorname{amargas}^{14}$; aquí, se desarrolla una risa rebelde ante la soledad metafísica del hombre, ante la muerte de Dios y de los grandes mitos que nos cobijaban: «Al gran poeta lírico no le contestó nada», escribe Silva en «La respuesta de la Tierra».

12 Aquileo J. Echeverría, Concherías (San José: Editorial Estatal a Distancia, 2011). La primera edición de Concherías es de 1905; la segunda de 1909, con un prológo de Rubén Darío, publicación en Barcelona. (N. de la E.).

13 Álvaro Quesada Soto, «Elementos críticos en las concherías de Aquileo J. Echeverría», en Echeverría, 220.

14 Publicado inicialmente en el tomo Poesías (Barcelona: Imprenta de Pedro Ortega, 1980). (N. de la E.) 
En esta misma época, Darío también percibió la ruptura que supone la llegada de la Modernidad, junto a los dos caminos que a partir de entonces se abrían. Escribir en verso no equivale a conectarse con un ideal de belleza o de verdad, lo que produce dos reacciones, opuestas pero igualmente modernas: por un lado, el intento de extremar los procedimientos retóricos para recuperar la poesía como último bastión de la metafísica; por otro lado, la asunción de la ruptura y la consecuente introducción de lo «bajo» en el interior de los poemas. El mundo de la risa está presente en ambos casos: en el primero a través del simbolismo tradicional y el hermetismo; en el segundo, mediante la utilización de referentes cotidianos, la mezcla de lenguajes y el humor explícito. En tal sentido, la ironía será una de las formas privilegiadas por la Modernidad.

El primer camino es el que hizo famoso a Darío. En su primera etapa, representada sobre todo por las Prosas profanas, el objetivo era multiplicar las correspondencias internas en el poema (rimas, ritmos, aliteraciones, paralelismos, quiasmos, sinestesias, etc.), como una suerte de conjuro que intentara abrir la realidad a una dimensión superior. El propio hecho de formular un proyecto explícito desvela las dificultades de conectarse con esa dimensión, cuya lejanía suele ser tema de lamento; por ejemplo, en el conocido poema «Yo persigo una forma que no encuentra mi estilo», en que el poeta solo consigue «la palabra que huye» y «el abrazo imposible de la Venus de Milo» ${ }^{15}$. Y de ahí el interés por el hermetismo como forma de recuperar la armonía entre hombre y mundo. Lo comprobamos en uno de sus poemas más conocidos, el «Coloquio de los centauros»: «hay un alma en cada una de las gotas del mar; / el vate, el sacerdote, suele oír el acento / desconocido ${ }^{16}$. De esta manera, el poeta, que había perdido la primacía sociopolítica, reclama su importancia en el mundo espiritual (argumento que sigue utilizándose hasta hoy en día).

15 Rubén Darío, Poesía (Caracas: Ayacucho, 1977) 240.

16 Darío, 201. 
Existe otra vía moderna para intentar la reconexión con la trascendencia. Se trata de las distintas variantes - no muy variadas realmente - de la poesía pura, en la senda de Mallarmé. Es una radicalización de la depuración estilística que se le supone a la poesía. Es decir, en lugar del exceso de Rubén Darío, se prefiere la ascesis. Esta vía también necesita, quizás de forma más imperiosa, el uso del símbolo y la visión estética del hermetismo. Nótese que el conocido grupo italiano que albergaba a Ungaretti, a Montale y a Quasimodo es conocido con el nombre de «hermetismo». Además, en estos poetas puede notarse la vinculación con movimientos vanguardistas, como el propio surrealismo, con los que comparten procedimientos «mágicos» para lograr la trascendencia, el acceso a una verdad suprema (llámese «divinidad»o «subconsciente»).

Volviendo a Darío, en un momento posterior optará por el segundo camino estético, el del prosaísmo. Suele justificarse esta etapa, representada por Cantos de vida y esperanza, en razón de un hastío vital o de un compromiso político del autor en el enfrentamiento entre Latinoamérica y Estados Unidos. Desde una perspectiva más amplia, se produce un compromiso con el mundo terrenal y con sus imperfecciones. Y es aquí donde entra la risa, como consecuencia de la ruptura y como estrategia para enfrentarse a la recién descubierta realidad cotidiana. Leamos el comienzo del poema «Agencia»:

¿Qué hay de nuevo?... Tiembla la Tierra.

En La Haya incuba la guerra.

Los reyes han terror profundo.

Huele a podrido en todo el mundo.

No hay aromas en Galaad.

Desembarcó el marqués de Sade

procedente de Seboim.

Cambia de curso el gulf-stream.

París se flagela de placer. 
Un cometa va a aparecer.

Se cumplen ya las profecías

del viejo monje Malaquías.

En la iglesia el diablo se esconde.

Ha parido una monja... (¿En dónde?...) $)^{17}$.

Desde el título sabemos que el sujeto poético se enfrenta a la actualidad, tal y como la transmite una agencia de noticias. La composición del poema se basa en la yuxtaposición de eventos y observaciones negativas, sin conexión aparente, por lo que la rima genera efectos irónicos. Estamos ante un «mundo al revés» satirizado y celebrado mediante el humor negro. Existe, por otro lado, una vinculación con los poemas anteriores de Rubén Darío a través de los referentes herméticos, especialmente los bíblicos, con énfasis en el Apocalipsis.

Las dos etapas que exploró Darío remiten a una nueva concepción del imaginario poético, que ya es plenamente moderno. El problema del Modernismo, como suele suceder con los movimientos exitosos, fueron los epígonos, que durante decenios produjeron una poesía que imitaba los rasgos formales de Darío a manera de ornamentos, sin asociarla en una visión de mundo. Es en estos casos cuando la poesía se vuelve objeto decorativo, no porque hable de jarrones chinos y de princesas nórdicas, sino porque se limita a la reproducción mecánica de procedimientos formales.

\section{Risa y poder: Roque Dalton}

En este contexto, el caso de Roque Dalton (1935-1975) se revela especialmente significativo. El principal objetivo, o al menos el declarado, del poeta salvadoreño no era el logro artístico, sino el cambio social a través de la palabra, como vía complementaria a la armada, que además ejerció. Con esta premisa, el lector esperaría una poesía directa con poco o ningún espacio para el simbolismo o

17 Darío, 354. 
el chiste. Muy al contrario, toda la poesía de Dalton se ubica en el universo de la risa, de donde toma los recursos para la lucha hacia la renovación de la humanidad. Lo que sucede es que en ocasiones esta risa puede contravenir las apariencias. Veremos el complejo juego que se establece en la poesía de Dalton en un poema aparentemente sencillo: «Las rimas en la historia nacional»:

Rimas salvadoreñas antes de 1972:

El que fue a Sevilla perdió su silla hartate un huevo con mantequilla porque aquí viene don Pancho Villa con sus dos putas a la orilla me cojo a tu tía simplemente María chiquilla mía.

Rimas salvadoreñas después de 1972:

El que fue a Sevilla perdió su silla guerrilla, guerrilla, guerrilla guerrilla, guerrilla, guerrilla, guerrilla guerrilla, guerrilla, guerrilla, guerrilla, guerrilla ${ }^{18}$.

Vamos a proponer dos lecturas diferentes para esta pieza. En la primera, nos guiaremos por lo que sabemos de Dalton y de su compromiso ideológico. Una lectura literal del poema advierte que en 1972 se propone como fecha de corte para un cambio en la poesía salvadoreña. Antes, las rimas parecen insignificantes y pueriles, como si fueran un entretenimiento vacío (y, en este sentido, existiría una risa paródica contra este tipo de poesía). Después, se impone la palabra «guerrilla» como forma de marcar el fin del juego y el imperativo de la lucha contra el poder establecido. Claro que esa lucha genera un nuevo poder que intenta imponerse por medio de la seriedad dogmática.

18 Roque Dalton, Historias y poemas de una lucha de clases (México: Ocean Sur, 2010) 77. 
La segunda lectura nos muestra un panorama completamente distinto. En efecto, las rimas «antes de 1972» siguen pareciendo lúdicas y pueriles, pero esta caracterización no tiene una connotación negativa, sino que entronca con la risa popular, que muchas veces se expresa en el lenguaje infantil como bien entendió Alfonso Reyes, aquí hay un gran campo para el desarrollo de la jintanjáfora, subversiva en cuanto no puede ser limitada a un único sentido. En este orden de cosas, «después de 1972» no supone un verdadero cambio estético: las rimas, repetidas abusivamente, pertenecen igualmente al universo de la risa y al humorismo naïf. En definitiva, todo el poema es una broma en verso, y no puede desprenderse de aquí ningún llamamiento al dogmatismo armado.

Así pues, la obra de Dalton se mueve en una contradicción, agónica o voluntaria, entre la premisa del poema como herramienta de cambio social (es decir, como poder) y la estética plenamente humorística, moderna, en que se inserta. Si consideramos la realidad concreta de su poesía, podríamos convenir en que manifiesta un carácter subversivo, no tanto por su faceta crítica, sino por la conexión con el realismo grotesco tradicional, es decir, con la esfera popular (al contrario de tantos movimientos populistas dirigidos por una élite dogmática).

Para proponer este imaginario subversivo, Dalton solía asumir figuras de la risa, en especial la del loco, por su capacidad de entender el mundo desde una perspectiva lejana a la oficial. Como dice en uno de sus versos, a los locos «no nos quedan bien los nombres», es decir, las categorías cerradas del lenguaje elevado. Elijamos como ejemplo un poema, «A la carta»: 
Sírvame la ópera Madame Butterfly

término medio

con salsa de maní picante

y un poco de gobierno español

con trocitos de invierno.

Después me trae a un soldado de la Primera Brigada de Artillería en completo estado de ebriedad

un par de mirtos

la erupción del Krakatoa

y el servicio postal a la luz de la filosofía.

De beber

algo que no desmaye en su difícil pero honrosa tarea.

Los postres se los pediré después.

\section{Ah}

y palillos de dientes ${ }^{19}$.

El texto parece salido de un perturbado que se hace pasar por miembro de la casta dominante, pero que lo confunde todo. En este sentido, recuerda la popular fiesta de los locos: el nombramiento del obispo de los locos en un ambiente carnavalesco. Al mismo tiempo, por supuesto, se propone una parodia que ridiculiza las costumbres y el lenguaje de la clase alta. No hay, en todo caso, el intento de situar un dogma superior. Más bien, recuerda la propuesta de Dalton en otro de sus versos: «La alegría es también revolucionaria, camaradas».

Desde esta perspectiva, es posible proponer una revaluación del libro al que pertenece el poema «Las rimas en la historia nacional». Se trata de Historias y poemas de una lucha de clases, también denominado Poemas clandestinos, que estaba escribiendo Dalton en medio de la lucha guerrillera, y quedó incompleto cuando el poeta fue

19 Roque Dalton, Un libro levemente odioso (San Salvador: UCA Editores, 1997$) 77$. 
asesinado por sus propios compañeros. La crítica ha minusvalorado este libro por considerarlo panfletario y de nulo valor poético; por estas mismas razones, algunos comentaristas «revolucionarios» lo exaltan. Ambas lecturas están sesgadas por partir del principio de seriedad.

Resulta revelador el hecho de que el libro se presente como una antología de diversos poetas salvadoreños. La heteronimia, que introduce cierta polifonía en el conjunto de la obra, es una estrategia de distanciamiento que debería ponernos en alerta desde el principio. Tomemos ahora una de las secciones, cuyo título pareciera excluir la risa: «Historias y poemas contra el revisionismo salvadoreño». Los poemas, sin embargo, no parecen escritos por un ideólogo, sino más bien por un niño, un tonto o un loco, cuya mirada utiliza Dalton para ridiculizar los dogmatismos, incluidos los propios.

Quizás el poema más emblemático en este sentido sea «Lógica revi», en que se produce una reductio ad absurdum de proclamas como «Una crítica a la Unión Soviética / solo la puede hacer un antisoviético» y «Una crítica al Partido Comunista Salvadoreño / solo la puede hacer un agente de la CIA», por lo cual «Una autocrítica equivale al suicidio ${ }^{20}$. Todo el poema está entrecomillado, con lo que queda claro el distanciamiento del autor (que, además, es un heterónimo de Dalton). En cuanto a la ridiculización del revisionismo, la «Parábola a partir de la vulcanología revisionista», cuyo título es en sí mismo delirante, atribuye al volcán Izalco una evolución ideológica desde el ultraizquierdismo hasta la civilización. En otros casos, el universo de la risa permea el poema de manera más sutil. Por ejemplo, en «Consejo que ya no es necesario en ninguna parte del mundo pero que en El Salvador», de título incompleto y más largo que el propio poema, que no deja de ser, por otro lado, una suerte de trabalenguas: «los menos fascistas / de entre los fascistas / también son / fascistas» ${ }^{21}$.

20 Dalton (2010), 55.

21 Dalton (2010), 51.

52 


\section{Las rupturas por la risa en la poesía costarricense moderna}

Queda claro, entonces, que las estéticas modernas no pueden prescindir de la risa, aunque se diferencien dos opciones aparentemente contrapuestas, que hemos repasado con Darío: el intento de reconexión con la trascendencia a partir del simbolismo y la introducción explícita de elementos tradicionalmente relegados por pertenecer a la esfera de lo «bajo». Dando un paso más, podríamos proponer la hipótesis de que la sucesión de movimientos estilísticos $\mathrm{y}$ de generaciones literarias a menudo esconde un simple movimiento pendular entre ambos extremos. Es el caso de Costa Rica.

Los mejores estudiosos de la poesía nacional, como Carlos Francisco Monge ${ }^{22}$, perciben una alternancia de poetas en búsqueda de lo inefable frente a otros que optan por una visión materialista de la existencia. Por supuesto, hay matices y énfasis que diferencian las sucesivas versiones de cada estética, por lo que es posible pensar en una historia de la poesía contemporánea que se mueva en espiral, y no en círculos. Con todo, se trata siempre de una simplificación pedagógica, porque ambos extremos aparecen en los autores con distinto grado de hibridación. En cualquier caso, queda clara la inadecuación del modelo de la historiografía tradicional, basado en una línea recta.

Vamos a recordar algunos casos. Comencemos por Eunice Odio (1919-1974), en libros como Los elementos terrestres ${ }^{23}$. Se ha resaltado la vinculación de la poeta con el surrealismo, pero lo importante no es la reproducción de ciertas imágenes y técnicas, sino el modo como la autora usa estos procedimientos vanguardistas para intentar conectarse con una realidad superior. Así, el erotismo de sus poemas, además de ser un gesto audaz de liberación feminista, es el

22 Ver Carlos Francisco Monge, La imagen separada: modelos ideológicos de la poesía costarricense (San José: Instituto del Libro, 1984) y Antología crítica de la poesía de Costa Rica (San José: Editorial Universidad de Costa Rica, 1993). (N. de la E.)

23 Eunice Odio, Los elementos terrestres (Guatemala: El Libro de Guatemala, 1948). Se cita por la edición de San José: Editorial Costa Rica, 2014. 
punto de partida para propiciar esa conexión, de claras resonancias místicas: «mi sexo como el mundo / diluvia y tiene pájaros. / Y me estallan al pecho palomas y desnudos. / Y ya dentro de ti / yo no puedo encontrarme» ${ }^{24}$. Nótese que, a diferencia de la mística tradicional, se necesita algo concreto, otro cuerpo, para alcanzar esferas superiores. Por otro lado, destaca en el poema la presencia de un simbolismo que aparenta ser mágico: pájaros que aparecen en lugares inverosímiles.

En el otro extremo, suele señalarse la gran influencia que tuvo la obra de Jorge Debravo (1938-1967) a partir de los años sesenta. La importancia y novedad en su contexto radica en haber proyectado la mirada hacia la realidad tangible, y en reflejarla a través de un lenguaje cotidiano. Cuando todavía se piensa la poesía en términos clásicos, en un lenguaje elitista y autosuficiente, escribir sobre la novia del carpintero o sobre el problema de la repartición de tierras resulta impactante, aunque no fuera, desde luego, una novedad absoluta. Con todo, el caso de Debravo es peculiar, porque no termina de aceptar las limitaciones del mundo terrestre $\mathrm{y}$, por motivaciones humanistas o políticas, suele mantener la tensión hacia un Bien mayúsculo. Encontramos aquí ecos del caso Roque Dalton, aunque de manera contenida.

Otras poetas de la época, como Carmen Naranjo (1928-2012) o Virginia Grütter (1929-2000), reflejan mejor el desencanto ante una unidad imposible y una realidad fragmentada: "Hay una vasta selva de caminos quebrados, / de trozos de ventana, / de nombres en pedazos ${ }^{25}$. Si no hay caminos firmes que recorrer, ni mirada compacta, ni siquiera palabras unívocas, a la poesía solo le queda explorar las ruinas y renunciar al lenguaje cerrado. Al respecto, se pueden establecer paralelismos con la narrativa. Recordemos, por ejemplo, la disolución del «yo» en las novelas de Yolanda Oreamuno, o la fragmentación social en Diario de una multitud, de Carmen

24 Odio, 23.

25 Virginia Grütter, Poesía de este mundo (San José: Editorial Costa Rica, 1973$) 42$. 
Naranjo ${ }^{26}$. En general, la novela muestra mayor capacidad para lograr un reacomodo de los elementos estéticos diseminados tras la ruptura de la unidad dogmática y, quizás por ello, sea el género dominante en la actualidad.

La poesía, en cambio, todavía ofrece intentos de recomponer, a pesar de todo, una visión metafísica de la existencia. Lo comprobamos en el siguiente movimiento pendular, bien representado por el Manifiesto trascendentalista (1977) ${ }^{27}$, de elocuente título. El proyecto de sus autores proponía, en esencia, una poesía que fuera más allá de las circunstancias concretas, que pudiera «develar» un misterio superior. Para lograrlo, se cuestionaba la espontaneidad del coloquialismo y se prefería un lenguaje abstracto y simbólico que buscara la sugerencia, incluso el hermetismo. Interesa resaltar que estos poetas justificaban su propósito no solamente con argumentos esencialistas («la poesía siempre ha sido esto»), sino también como forma de oposición al materialismo capitalista, mismo objetivo de Roque Dalton o Jorge Debravo, autores aparentemente opuestos. El choque frontal entre la poesía moderna y la ideología burguesa, como ya habíamos visto, proviene de la separación entre poesía y poder, lo que también ha sido acicate para la renovación y apertura del género poético.

Vamos a referirnos brevemente a la evolución poética de dos de los poetas citados, que terminaron escapando del modelo inicialmente propuesto. Por un lado, Laureano Albán (1942) representa un caso muy singular en el panorama continental, comparable a Ernesto Cardenal. Lo peculiar aquí es cómo se combina el interés por la multiplicidad diacrónica (historia de América ${ }^{28}$ )

26 Carmen Naranjo, Diario de una multitud (San José: Editorial Universitaria Centroamericana, 1974). (N. de la E.)

27 Laureano Albán, Julieta Dobles, Ronald Bonilla y Carlos Francisco Monge, Manifiesto trascendentalista (San José: Editorial Costa Rica, 1977).

28 Visible en obras suyas como Chile de pie en la sangre (1975) o Biografias del terror (1984). (N. de la E.) 
y sincrónica (su Enciclopedia de maravillas $^{29}$ ) con una mirada unificadora y trascendente. Para ello, acude a subtextos míticos de distintas culturas, como las prehispánicas ${ }^{30}$. Este procedimiento, que encontramos en textos seminales de la Modernidad (La tierra baldía de Eliot, el Ulises de Joyce), manifiesta la paradójica importancia, en el imaginario moderno, del simbolismo tradicional para enfrentarse a la muerte de Dios.

Porotro lado, resulta significativa la trayectoria de Carlos Francisco Monge (1951) que partiendo del ya mencionado trascendentalismo, ha desarrollado en los últimos años una mirada irónica. Esto supone un cambio de extremo, puesto que se pasa del intento de reconexión simbolista al reconocimiento de la desconexión entre las palabras y los imaginarios que construyen. De esta manera, el poeta puede asimilarse al «perro callejero»: «No hay imagen heroica, ni estampa, ni esplendor, / ni resignación siquiera; / hay en cambio calambres, innumerables señas / de su amor por el bote de basura, / por el descampado» ${ }^{31}$. La intemperie, el amor por la basura, tienen en el poema unas connotaciones melancólicas, como signos de derrota, que también pueden interpretarse como un nuevo comienzo.

De hecho, esta exploración de las ruinas caracteriza a la poesía que se está escribiendo ahora mismo en Costa Rica. Se trata de una nueva versión del materialismo poético. A los rasgos comunes de esta opción estética, como los referentes concretos y el lenguaje cotidiano, se añade un particular énfasis en la risa como forma de desacralización. También se utilizan muchos referentes de la cultura de masas, que puede entenderse como una cultura popular internacional que unifica el imaginario de la humanidad con los medios de comunicación masivos. La referencia a películas como «Star Wars», o incluso a productos como la Coca-Cola, a menudo

29 Laureano Albán, Enciclopedia de las maravillas (Pittsburgh: International Poetry Forum, 1995).

30 Véase, por ejemplo, Laureano Albán, Infinita memoria de América (Madrid: Sociedad Estatal Quinto Centenario, 1991).

31 Véase Carlos Francisco Monge, Poemas para una ciudad inerme (San José: Editorial de la Universidad Estatal a Distancia, 2009). (N. de la E.) 
se percibe como un aspecto novedoso, pero en realidad supone una manifestación renovada del simbolismo tradicional. Al fin de cuentas, gran parte de las películas de éxito (la mencionada «Star Wars», «Harry Potter», «Batman», etc.) se basan en el esquema hermético de la lucha del bien contra el mal.

Quisiera referirme a un poeta que ha pasado casi desapercibido en su país, a pesar de haber ganado algunos importantes premios internacionales. Se trata de Klaus Steinmetz (1961); La yema del tiempo $^{32}$ es particularmente interesante puesto que demuestra las posibilidades que genera la unión de las dos tendencias que hemos venido estudiando. La «yema» sería el universo simbólico presente en diversas épocas y personajes, a través de las metamorfosis en los sujetos poéticos de este largo poema; el «tiempo» sería la apariencia de movilidad de los personajes y de los sucesos históricos en la concreta ciudad de San José. La oposición entre ambos elementos es el tema del poema: «El mundo es, entonces, dos (...) / Al mirarlo todo / mis ojos no miraban nada / acaso solo el detalle / que introduce una astilla / en el pulmón de los sucesos / y los delata. // Imaginaria ${ }^{33}$. Vemos aquí el choque entre el mundo aparente de las circunstancias y la mirada más profunda. De otra manera, más prosaica: «Vistos desde lejos / un chiíta y un sunnita son ambos musulmanes» ${ }^{34}$.

\section{La «novelización» de la poesía: Luis Chaves}

El proceso de la poesía moderna podría resumirse en lo que Bajtín llamaba «novelización» de la poesía. Con este término, el teórico ruso se refería a la ruptura del lenguaje elevado y autosuficiente, y la consecuente inclusión de otros lenguajes y visiones de mundo. En este sentido, la poesía moderna se acercaría a la novela, que se define por el carácter dialógico de su discurso, abierto al contexto

32 Klaus Steinmetz, La yema del tiempo (San José: Germinal, 2008).

33 Steinmetz, 11.

34 Steinmetz, 48. 
sociohistórico que permea sus palabras.

Todos estos rasgos los veremos con cierto detenimiento mediante el estudio del poeta costarricense más conocido hoy día, tanto en su país como fuera de sus fronteras: Luis Chaves (1969). La publicación de sus libros en grandes editoriales de España, México o Argentina, así como la inclusión de su nombre en varias antologías importantes de poesía hispanoamericana, son indicios de que su propuesta estética conecta con las búsquedas actuales. En otras palabras, la poesía de Chaves no solo interesa por sí misma, sino también por ser representativa de nuestro momento, al igual que sucede con otros nombres contemporáneos como el dominicano Frank Báez, el mexicano Luis Felipe Fabre o el argentino Wáshington Cucurto.

El título de su poesía completa publicada en 2016 es significativo: Falso documental ${ }^{35}$. Por un lado, enlaza con el objetivismo tan explícito en la poesía argentina de los noventa (recordemos las Tomas para un documental de Daniel García Helder); por otro, el género del falso documental («mockumentary») permite cuestionar las divisiones entre lo real y lo imaginario a través de la risa. Pero, sobre todo, se produce una gran tensión al titular un libro de poemas con un referente narrativo. Precisamente, este conflicto es el que más parece preocupar al poeta o al sujeto poético: «Hay que decidirse: / verso o prosa», lo que un poco más abajo se compara a la dicotomía «cáncer o accidente» ${ }^{36}$. El cáncer, añadimos, sería la novela, que parece provocar un proceso descontrolado en la división celular de los otros géneros.

Comencemos con Chan Marshall ${ }^{37}$, libro que adopta el nombre familiar de la cantante conocida como «Cat Power». Mientras que algunos poemas parecen referirse a la vida de la artista estadounidense, otros se ubican en un contexto más cercano al propio poeta (el protagonismo de la ciudad de San José), mientras que el "Grandioso

35 Luis Chaves, Falso documental: poesía completa 1997-2016 (Buenos Aires: Seix Barral, 2016).

36 Chaves (2016), 34.

37 Luis Chaves, Chan Marshall (Madrid: Visor, 2005). 
bingo" final recoge una multiplicidad de personajes en un casino. Lo que todas las piezas tienen en común es «la inutilidad / de escribir en verso / lo que a todas luces es prosa $)^{38}$. Una prosa en verso que se dedica a narrar historias. Leamos una de ellas, titulada «SJB 2114»:

La Peri rodea San José con un foco dañado.

De lo que vio durante el día, el chofer no extrae conclusiones.

Dentro de poco, el albino que bajó en Colonia Kennedy reclamará a la esposa, «si no lo hubieras alimentado con tanta verdura nuestro hijo no sería maricón $»^{39}$.

Así como la vertiente trascendentalista se había caracterizado por un esfuerzo de abstracción que buscaba captar destellos de una realidad invisible, este poema de Chaves se regodea en la aparente banalidad con que narra una serie de detalles o de escenas vagamente conectados. Al igual que al chofer, al lector se le dificulta extraer conclusiones. Con todo, es sencillo percibir al menos un rasgo que unifica al chofer, al albino, a su hijo, e incluso al foco del autobús: la posición periférica, desplazada respecto a las normatividades tradicionales. También es esta la posición del poema respecto a la literatura después de la pérdida de la mitificación.

Para confirmar este punto, pasemos a un breve poema en prosa, «Teológica»: «Aquellas vacaciones prometimos creer en Dios si te bajaba la regla. No te vino. Tampoco somos padres. Y Dios, bueno, será mejor que de verdad no exista» $»^{40}$.

38 Chaves (2005), 194.

39 Chaves (2005), 227.

40 Chaves, 255. 
Lo que se calla a través de la elipsis es un tema tabú en Costa Rica: el aborto. Sin embargo, el hecho de que el poema sea la última pieza del libro nos permite interpretarlo en clave metapoética: no hay un misterio al que acceder más allá de las palabras y, si lo hubiera, la verdad es que no podría alcanzarse con este tipo de poesía, ya totalmente entregada a la Modernidad. Y la Modernidad estética se caracteriza por un profundo movimiento hacia la igualación y, en consecuencia, hacia la identidad individual. No hay, por lo tanto, un ideal que suscite la identificación de nosotros como un colectivo.

Este movimiento promueve la novelización de la poesía. Un ejemplo más claro en este sentido es el siguiente libro de Luis Chaves, Asfalto, un road poem $^{41}$, publicado primero como poesía y años después como novela corta. El hecho de que estar escrito en prosa facilita la confusión, pero en realidad su estética no difiere del libro en verso que acabamos de comentar. Si acaso, existe en Asfalto una mayor unidad entre las piezas, que comparten unos mismos protagonistas y escenarios, en torno a un viaje en automóvil, con sus gasolineras, moteles de paso y encuentros con otros viajeros. Recuerda a El mapa de América, libro en prosa de un poeta español contemporáneo a Chaves, Pablo García Casado. Son ejemplos de otro viaje más profundo: el de la poesía en busca de su lugar en el mundo moderno.

En definitiva, en la Modernidad la poesía rompe toda vinculación con el bien o la belleza. En este nuevo paradigma, la risa es tanto la consecuencia como la herramienta de la ruptura. Consecuencia, porque se produce un choque cognitivo entre lo que se espera del discurso poético y lo que se ofrece en estos poemas prosaicos. Por esto el humor está incluso cuando no se lo espera. Y la risa también como herramienta de la ruptura, porque con ella es posible introducir elementos anteriormente excluidos de la poesía. Pensemos en un título como Chistes para desorientar a la poesía ${ }^{42}$, de Nicanor Parra. «Desorientar», desde su prefijo, supone una negación, incluso una

41 Luis Chaves, Asfalto: es un road poem (San José: Ediciones Perro Azul 2006).

42 Nicanor Parra, Chistes para desorientar a la poesía (Santiago de Chile: Galería Época, 1983). 
destrucción. Pero, a través de esta destrucción, de esta poesía en ruinas, es posible pensar en una nueva libertad, en una «reorientación».

Entonces, ¿hacia dónde puede reorientarse la poesía? La respuesta más habitual, de los pensadores autodenominados posmodernos, apunta al pastiche, a la mezcla desintegrada. Subyace en esta concepción de aparente frescura el rancio prejuicio de que la poesía es completamente inútil. Ahora bien, si creemos que la poesía, que la literatura en general, desempeña algún papel para imaginar el mundo, estaremos de acuerdo en que esa imaginación busca un sentido, una dirección y un significado. Un sentido que, por otro lado, será siempre construido, no basado en un ideal dogmático. En esta búsqueda están los mejores poetas de la actualidad, así como sus mejores lectores. El hecho de que existamos es parte de ese sentido. 